\title{
Direct Evidence for Loss and Replacement of Projection Neurons in Adult Canary Brain
}

\author{
J. R. Kirn and F. Nottebohm \\ The Rockefeller University Field Research Center, Millbrook, New York 12545
}

\begin{abstract}
Normally occurring projection neuron loss and replacement were quantified over a 6 month period in the pathway from the high vocal center (HVC) to the robust nucleus of the archistrlatum (RA) in adult male canaries. Fluorescent latex microspheres were injected into RA in April-a procedure resulting in long-term retrograde labeling of RA-projecting HVC neurons. Labeled cell densities were then obtained 4 and $20 \mathrm{~d}$ later in April and $195 \mathrm{~d}$ later in October. We found that $41-49 \%$ of the RA-projecting HVC neurons present the previous April were no longer present in October. Fluorogold injections in RA 3 d prior to death in April and October retrogradely labeled similar overall densities of RA-projecting HVC neurons, indicating that cells lost over this 6 month period were replaced by new RA-projecting HVC neurons. Newer cells were larger than older cells, suggesting that an age-dependent reduction in size might precede death. Over the same time interval, no loss was observed for neurons projecting from the lateral magnocellular nucleus of the anterior neostriatum to RA. Thus, loss was specific to the input from HVC to RA. These findings raise the possibility that much if not all of the pathway from HVC to RA is replaced within a year. The time period examined encompasses the yearly transition from stable song to song learning in the canary (Nottebohm et al., 1986, 1987). A pronounced loss and replacement of neurons implicated in vocal control during this period may relate to the canary's ability to modify song in adulthood.
\end{abstract}

[Key words: adult neurogenesis, adult neuron death, neuronal replacement, telencephalon, song control, learning, birds, canary]

Neurons are produced and distributed throughout much of the telencephalon of adult birds (for review, see Nottebohm, 1985; Alvarez-Buylla and Nottebohm, 1988). One recipient region for new neurons is the high vocal center (HVC), a discrete forebrain area involved in the control of learned song (for review, see Nottebohm, 1989; Nottebohm et al., 1990). Most adult-formed HVC neurons become projection cells that connect the HVC with the robust nucleus of the archistriatum (RA) (AlvarezBuylla et al., 1990a; Kirn et al., 1991). RA, in turn, projects

\footnotetext{
Received July 23, 1992; revised Oct. 13, 1992; accepted Oct. 22, 1992.

We thank Jeffrey Cynx for help with computer software and Arturo AlvarezBuylla, Cynthia Seiwert, and David Vicario for critical readings of early drafts of the manuscript. This work was supported by grants from the NIH (NS29843 to J.R.K. and MH18343 to F.N.).

Correspondence should be addressed to John Kirn, RUFRC, Rural Route 2, Box 38B, Millbrook, NY 12545.

Copyright $\odot 1993$ Society for Neuroscience $0270-6474 / 93 / 131654-10 \$ 05.00 / 0$
}

onto the motor neurons that innervate the syrinx (Nottebohm et al., 1976). New neurons, therefore, are inserted into the efferent pathway for the control of learned song (Fig. 1).

Approximately $50-60 \%$ of the neurons in HVC project to RA (Alvarez-Buylla et al., 1990a; Kirn et al., 1991). When the cell bodies of these neurons are used to define HVC's boundaries, the volume they enclose remains constant in adult canaries over periods of up to 8 months extending from fall to the following spring (Kirn et al., 1991). Moreover, the total number of RAprojecting neurons does not change over the same interval (Kirn et al., 1991). This seemingly static picture, however, masks the dynamics of neuronal replacement within HVC. RA-projecting neurons are produced and incorporated into the adult $\mathrm{HVC}$ at rates as high as $0.3-0.5 \%$ per day (Alvarez-Buylla et al., 1990a; Kirn et al., 1991). These results suggest that some RA-projecting HVC neurons die and are replaced by new neurons of the same kind. Neuronal loss has never been demonstrated directly, however. Moreover, we do not yet know what proportion of cells in the circuit from HVC to RA are replaced. This information is necessary in order to determine whether adult ncuronal turnover is a common feature of projection neurons linking HVC to RA or is restricted to a small, perhaps specialized subpopulation of these cells.

Normally occurring addition and loss of RA-projecting HVC neurons may be related to adult song plasticity in the canary. Adult male canaries change their song every year. In April, song is loud and stereotyped; song is less stable in October, and by then many song components from the previous spring's repertoire have been deleted or modified and others have been added (Nottebohm et al., 1986, 1987). Recruitment of new RA-projecting $\mathrm{HVC}$ neurons is higher in the fall than in the spring (Alvarez-Buylla et al., 1990a). In addition, HVC neurons born in the fall survive at least 8 months, a sufficient length of time for them to participate in the yearly acquisition of new song in the fall and the retention of this song until the following spring (Kirn ct al., 1991). These results raise the possibility that the processes of neuronal addition and loss participate in both the formation and turnover of motor programs for song.

We wished to determine the number of RA-projecting HVC neurons that survive the transition from stable song in the spring to plastic song in the fall. The present experiment, therefore, was designed to obtain a direct evaluation of the percentage of RA-projecting HVC neurons that are lost and replaced during a time of year when song reorganization is at its highest.

\section{Materials and Methods}

Surgery. Adult male canaries (12-13 months old) from our close-bred colony of the Belgian Waterslager strain were deeply anesthetized with intramuscular injections of ketamine (Ketalar, Park-Davis; $0.5 \mathrm{mg} / 20$ 


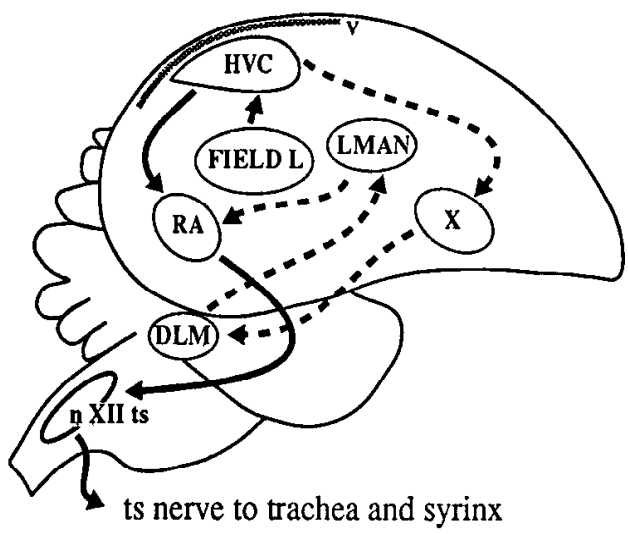

Figure 1. Schematic diagram of major circuitry of the song bird vocal control system (from Nottebohm et al., 1976, 1982; Bottjer et al., 1989). The focus of current work is on cells projecting from the high vocal center $(H V C)$ to the robust nucleus of the archistriatum $(R A)$. These neurons are produced in adulthood. $R A$ neurons also receive afferents from cells in the lateral magnocellular nucleus of the anterior neostriatum ( $L M A N)$. The efferent pathway for song control (shown with solid lines) includes $H V C$ and $R A, R A$ 's projection onto the motor neurons of the tracheosyringeal branch of nucleus XII ( $n X I I t s$ ), and the $n X I I$ $t s$ projection onto the syrinx, or vocal organ. A parallel, indirect pathway also exists between $H V C$ and $R A$ (shown with broken lines) consisting of a projection from $H V C$ to area $X$, a projection from $X$ to the dorsolateral nucleus of the thalamus $(D L M)$, a projection from $D L M$ to $L M A N$, and projections from $L M A N$ to $R A$.

gm body weight) and xylazine (Rompun, Haver; $1.0 \mathrm{mg} / 20 \mathrm{gm}$ body weight). Stereotaxic surgery and tracer injections were performed as described previously (Kirn et al., 1991). In early April, birds were placed in a stereotaxic instrument, a midline scalp incision was made, and the skin over the dorsal skull surface was retracted. The brain surface caudal to HVC was exposed by making a small hole in the skull. A glass micropipette loaded with undiluted fluorescent latex microspheres (Luma Fluor, Inc.) was then lowered into RA at a $9^{\circ}$ angle from the vertical with reference to the canary stereotaxic atlas (Stokes et al., 1974). In each hemisphere, microspheres (beads) were pressure injected into RA at four different sites $(10-20 \mathrm{nl}$ per injection, spaced $0.3 \mathrm{~mm}$ apart rostrocaudally and $0.2 \mathrm{~mm}$ apart in the dorsal-ventral axis) to produce maximal retrograde labeling of RA-projecting HVC neurons. Beads have been used as a long-term, nontoxic label for neurons in other systems (Katz et al., 1984; Divac and Mogensen, 1990), including other vocal control circuits (Gahr, 1990; Morrison, 1991).

Birds were then randomly assigned to one of three survival times. The experimental design is summarized in Figure 2. Animals were killed $4 \mathrm{~d}$ (early April), $20 \mathrm{~d}$ (late April), or $195 \mathrm{~d}$ (October) after bead injections. Two survival times in April were used to control for possible toxicity of beads to RA-projecting HVC neurons (also see other controls described below). If beads killed neurons, then a measurable loss of cells backfilled with beads might be seen during this initial $20 \mathrm{~d}$ survival period. Three days prior to death, canaries in the longer two survival groups were subjected to a second surgery in which the retrograde tracer fluorogold (Schmucd and Fallon, 1986; $2 \%$ in $0.9 \% \mathrm{NaCl}$; Fluorochrome, Inc.) was injected stereotaxically into each RA. These two tracers are easily distinguished under fluorescence microscopy.

Fluorogold injections made in April and October provided a measure of the overall density of RA-projecting neurons to which bead-labeled cell loss could be compared. The density of fluorogold-labeled HVC neurons backfilled from RA is comparable whether the fluorogold injections are the only injections given (Kirn et al., 1991), or they follow by $17 \mathrm{~d}$ the injection of fluorescent beads into RA (present study). From this we infer that injections of fluorescent beads into RA do not seriously impair the ability of RA-projecting HVC neurons to retrogradely transport fluorogold injected at a later time. The same conclusion can be drawn from the fact that sequential injections of fluorescent beads and fluorogold produce a majority of cells labeled with both markers. Fluorogold and beads injected into RA have also been shown to label similar numbers of HVC neurons (Kirn et al., 1991; present results). These observations reassure us about the appropriateness of using a doublelabeling method to quantify the loss and replacement of RA-projecting HVC cells over a 6 month period from April to October. Thus, in the present paradigm, fluorescent bead labeling was used to measure neuron loss between April and October. Assuming maximal backfills with both tracers, the majority of cells labeled exclusively with fluorogold would represent projection neurons inserted only after bead injections-an index of replacement.

To control further for possible effects of damage associated with in-

GRP 1

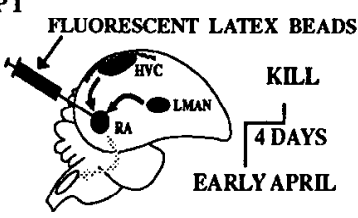

GRP 2
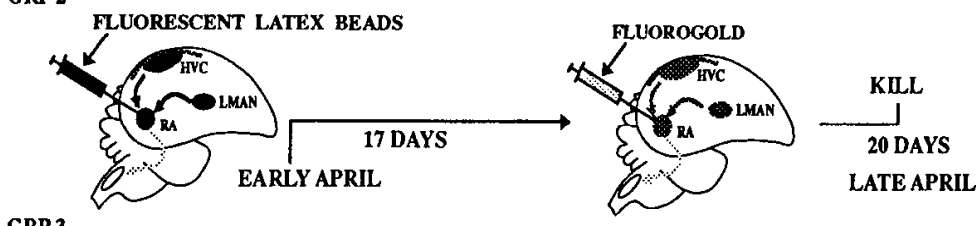

GRP 3

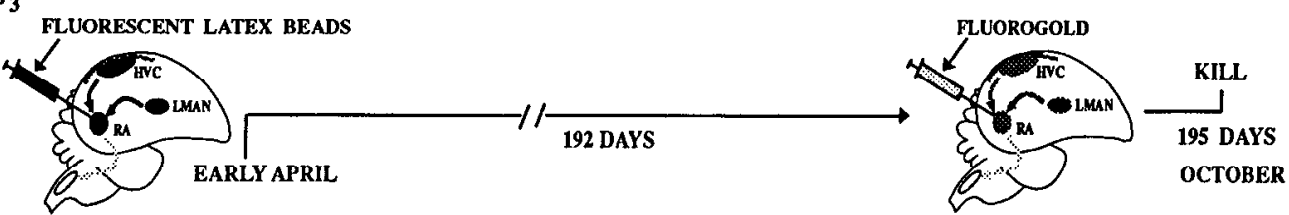

Figure 2. Schematic diagram of the experimental design. In April, adult male canaries were anesthetized and then fluorescent latex microspheres (beads) were pressure injected bilaterally into RA to retrogradely label neurons projecting to $R A$ from $H V C$ and $L M A N$. Following surgery, birds were randomly assigned to one of three groups with survival times of $4 \mathrm{~d}(n=4), 20 \mathrm{~d}(n=4)$, or $195 \mathrm{~d}(n=5)$. Beads provided a long-term marker with which to measure neuron loss. $R A$ in birds from the longer two survival groups was reinjected with the retrograde tracer fluorogold $3 \mathrm{~d}$ prior to death. Fluorogold label provided a basis for quantification of overall projection neuron densities in April and October. Double labeling signified that a neuron survived the duration of time between tracer injections. Neurons labeled with fluorogold and that did not also contain beads represented cells born after the bead injections. Based on previous work, we predicted that projection neurons arising from $H V C$ would exhibit loss and replacement but those in $L M A N$ would not. 

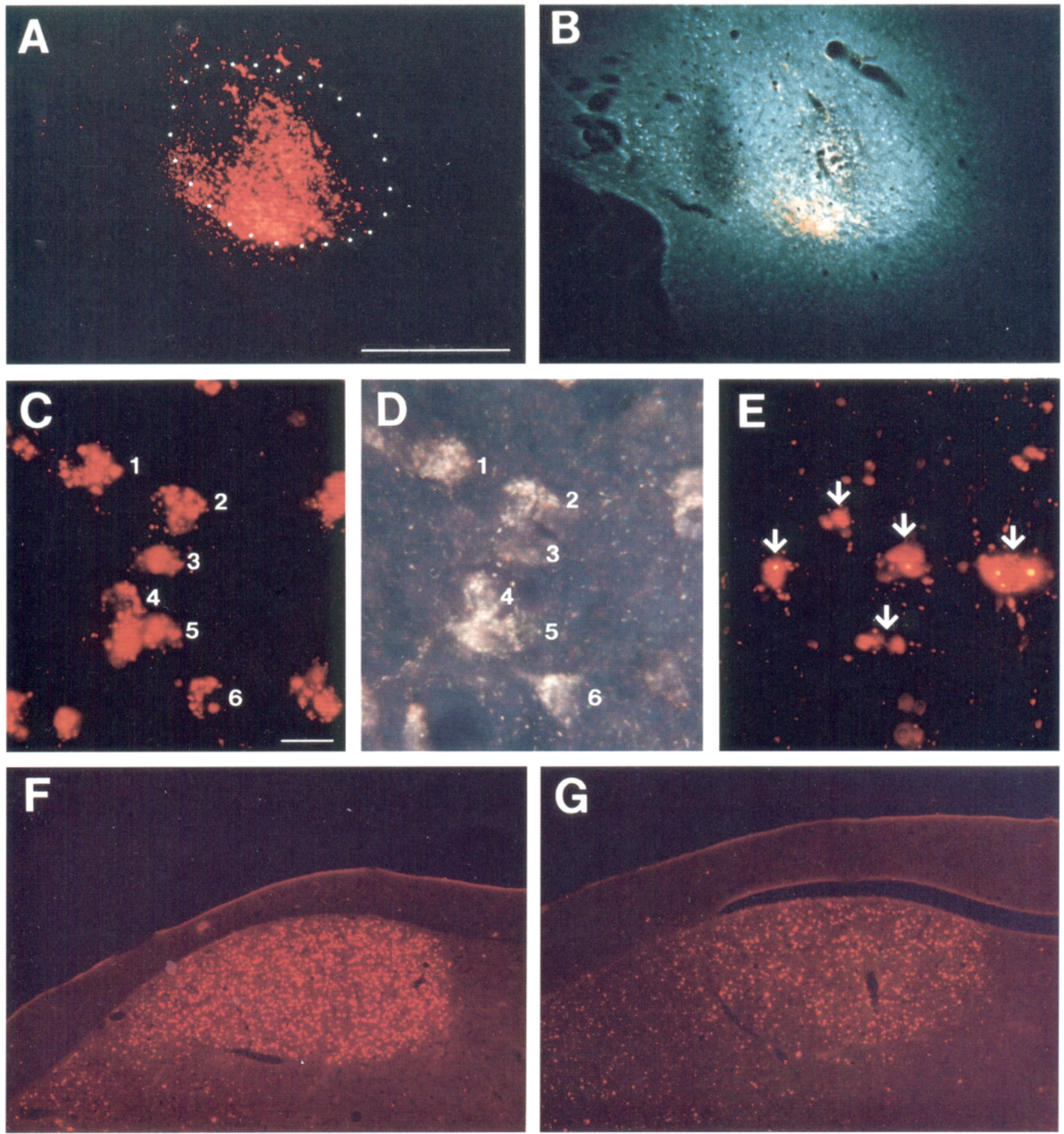

Figure 3. $A$ and $B$ are photomicrographs of a sagittal section through the injection sites of a bird killed $20 \mathrm{~d}$ after beads $(A)$ and $3 \mathrm{~d}$ after fluorogold $(B)$ were stereotaxically placed in RA. The two panels are of the same tissue field viewed with different fluorescent filter sets. Dorsal is up and rostral is to the right in these and all photomicrographs to follow. RA is an egg-shaped nucleus whose rostral pole can be seen in the center of the injection site in $B$. The approximate boundaries of RA have been delimited by dots in $A$. $C$ and $D$ show a higher-magnification view of $\mathrm{HVC} 20$ $\mathrm{d}$ after RA injections of beads and $3 \mathrm{~d}$ after RA was injected with fluorogold. Most cells originally labeled with beads $(C)$ became labeled with fluorogold subsequently $(D)$. $C$ and $D$ are views of the same tissue field. Numbers (1-6) correspond to examples of double-labeled cells. At 195 d survival $(E)$, beads tended to form aggregate clumps of intensely fluorescent material in the cytoplasm (arrows). The absence of a uniform cytoplasmic distribution of beads prevented their use in measurements of soma diameters. In contrast, fluorogold provided good definition of cell profiles, and so it was used for neuronal size measurements instead. $F$ and $G$ are photomicrographs of sagittal sections through HVC showing the pattern of bead labeling at short and long survival times. $F$ is from a bird killed in late April, $20 \mathrm{~d}$ after RA injections of beads. $G$ is of a comparable section from a bird killed the following October. Note the loss of bead-labeled neurons between the two survival times. Scale bars: $A, B, F$, and $G, 500$ $\mu \mathrm{m} ; C-E, 10 \mu \mathrm{m}$. 
jection procedures, nonspecific loss of beads over time, or group differences in the targeting of RA, we also examined the lateral magnocellular nucleus of the anterior neostriatum (LMAN). The most common type of RA neuron receives input from LMAN as well as HVC (Canady et al., 1988). Therefore, tracer injections in RA retrogradely label projection neurons with cell bodies in both of these brain areas. LMAN does not acquire new projection neurons in adulthood (Nottebohm, 1985; Alvarez-Buylla, 1992). Thus, we predicted that the density of LMAN neurons backfilled with fluorescent beads would not differ in April and October, while that of HVC backfilled neurons would drop.

Histology. Prior to death, subjects were given an overdose of anesthetic and perfused through the heart with $0.9 \% \mathrm{NaCl}$ followed by $4 \%$ paraformaldehyde in $0.1 \mathrm{M}$ phosphate buffer. Brains were removed and stored in the same fixative for $1-4$ weeks. Tissue was then submerged in $30 \%$ sucrose in $1 \mathrm{~m}$ phosphate buffer for $24 \mathrm{hr}$ and cut sagittally at a thickness of $20 \mu$ on a freezing microtome. Sections were collected in $0.1 \mathrm{M}$ phosphate buffer, and every third section was mounted onto gelatinized slides and air dried. Slides were coverslipped with immersion oil prior to viewing.

Quantification. All fluorescently labeled cells were counted in four equally spaced sections from the central two-thirds of $\mathrm{HVC}$ and two sections from an equivalent portion of LMAN using a $63 \times$ oil objective. Data were collected and stored on a computer-yoked fluorescence microscope system that has been described in detail elsewhere (AlvarezBuylla and Vicario, 1988). Cells were classified according to whether they were labeled with beads, fluorogold, or beads and fluorogold by alternating between different fluorescence filters (Nikon filter sets G1-A for beads and UV-1A for fluorogold). These label categories were not mutually exclusive and in animals that received both fluorogold and bead injections a given cell could have been assigned to all three classifications. Double-labeled cells were a subset of the total labeled with fluorogold and the total labeled with beads. Projection neuron densities were calculated by dividing the sum of labeled cells across all sections by the total area sampled. In each animal, soma diameters, as defined by cytoplasmic fluorescence, were obtained from at least $50 \mathrm{HVC}$ neurons and 20 LMAN neurons for each cell labeling category. Soma diameter information was used so that our corrected cell density measures took into account cell splitting (Weibel, 1979), and the corrected data were expressed as labeled neuron densities per unit volume.

Based on previous work (Kirn et al., 1991), adult-formed HVC neurons become smaller as they age, and we wished to determine in the present experiment whether this was true for the HVC-to-RA neuronal population. However, in our material, beads tended to aggregate into large, unevenly distributed intracellular compartments in birds at long survivals, making it difficult to resolve the precise boundaries of the cytoplasmic envelope in some cases (see Fig. $3 E$ ). In contrast, fluorogold backfills labeled the cell cytoplasm more uniformly. Therefore, statistical comparisons of mean cell diameter between cell categories and survival times were restricted to cases where fluorogold could be used for measurements. This procedure limited the number of comparisons to cells labeled with fluorogold and those that were double-labeled at 20 and 195 d survival. Frequency histograms of corrected cell diameters (Weibel, 1979) were constructed by adding the number of cells in each size class across animals within a survival time. Due to slight interanimal differences in the number of cells measured, summed values were then converted into proportions.

Statistics. After excluding animals with off-target tracer injections, sample sizes were $n=4$ for $4 \mathrm{~d}$ survival, $n=4$ for $20 \mathrm{~d}$ survival, and $n=5$ for $195 \mathrm{~d}$ survival. In all birds, targeting of RA injections was more satisfactory in one hemisphere than in the other and quantification was restricted to the side that showed the most complete tracer injections. All survival times included some birds with analysis done on the right side and some with analysis done on the left side [2 right $(R), 2$ left (L) in the $4 \mathrm{~d}$ group; 1R, 3L in the $20 \mathrm{~d}$ group; 1R, 4L in the 195 d group]. Although the longer two survival times favor the left hemisphere, we observed no tendency for left-right differences in cell loss and previous work has failed to show laterality in new HVC neuron incorporation (Alvarez-Buylla et al., 1990a; Kirn et al., 1991).

Statistical comparisons were made with one- or two-way analysis of variance (ANOVA), using survival time as an independent factor. Initial comparisons between HVC and LMAN were conducted with nucleus as a within-subject factor. A within-subject design was also employed when comparing different label categories (beads, double, and fluorogold) in the same birds ( 20 and $195 \mathrm{~d}$ survival times). When overall analyses yielded significant main effects or interactions $(p<0.05)$, planned pairwise comparisons were conducted using unpaircd $t$ tcsts for comparisons across survival times and paired $t$ tests for comparisons of different label categories within a survival time.

\section{Results}

\section{Injection sites}

Inspection of bead injection sites in all birds revealed similar targeting success across the three survival times. Large deposits of beads remained in RA and surrounding archistriatum irrespective of survival time. An example of injection sites in RA after sequential administration of beads and fluorogold is shown in Figure 3, $A$ and $B$, respectively. In all animals, beads and fluorogold injections overlapped with each other extensively. Beads tended to diffuse over shorter distances than fluorogold, despite having injected the same volume of the two retrograde tracers. Thus, fluorogold injections appeared to fill RA, as well as regions surrounding $\mathrm{RA}$, more completely than beads. However, terminal fields within RA for HVC-to-RA projection neurons are extensive (Vicario and Simpson, 1988), and so comparable patterns of marker uptake may obtain even when injections are not identically placed and when the tracers used show somewhat different sprcad. This argument is supported by previous work (Kirn et al., 1991) in which the two tracers labeled comparable numbers of HVC neurons-a result also obtained in the present experiment (see below).

\section{$H V C$ labeled cell densities}

Following sequential RA injections of beads and fluorogold, most $\mathrm{HVC}$ cells originally labeled with beads became labeled with fluorogold as well (Fig. $3 C, D$ ). Figure $3, F$ and $G$, shows representative sagittal sections through HVC from canaries killed 20 or $195 \mathrm{~d}$ after labeling the HVC-to-RA projection neurons with beads in April. Between these two survival times a noticeable decrease was found in the density of bead-labeled cells.

Mean ( \pm SEM) bead-labeled cell densities for the April cohort of $\mathrm{HVC}$ neurons at the three survival times are summarized in Figure $4 A$. Estimates of the overall density of RA-projecting HVC ncurons in late April and October, as determined by fluorogold injections made $3 \mathrm{~d}$ prior to death, are also included. For comparison, the densities of double-labeled projection neurons (beads + fluorogold) are also presented. Beads tended to clump together over long survivals (see Fig. 3E)-a phenomenon that has also been observed in other systems (Madison et al., 1990; L. Katz, personal communication). This resulted in an uneven distribution of label in the cell cytoplasm. In contrast, fluorogold labeled the cytoplasm more completely. The fluorogold label provided a secondary marker that aided in discriminating between cases where two clumps of beads were contained within a single cell and cases where two clumps of beads represented two closely packed cells. Fluorogold label also provided confirmation that a cell labeled with beads was a neuron, rather than a phagocyte or glial cell that may have incorporated beads along with other debris associated with neuronal degeneration.

ANOV $\Lambda$ revealed that our labeling methods yielded different densities of RA-projecting cells, irrespective of survival time [main effect, $F(2,6)=139.7, p=0.0001$ ]. Fluorogold and beads were equally sensitive markers as shown by the fact that they produced similar densities of labeled neurons in birds killed in late April $[t(3)=0.69 ; p=0.54]$. However, densities of doublelabeled cells were consistently lower than densities of beadlabeled cells irrespective of survival time [in late April and October, respectively: double/beads $=0.90, t(3)=4.34, p=$ 
A

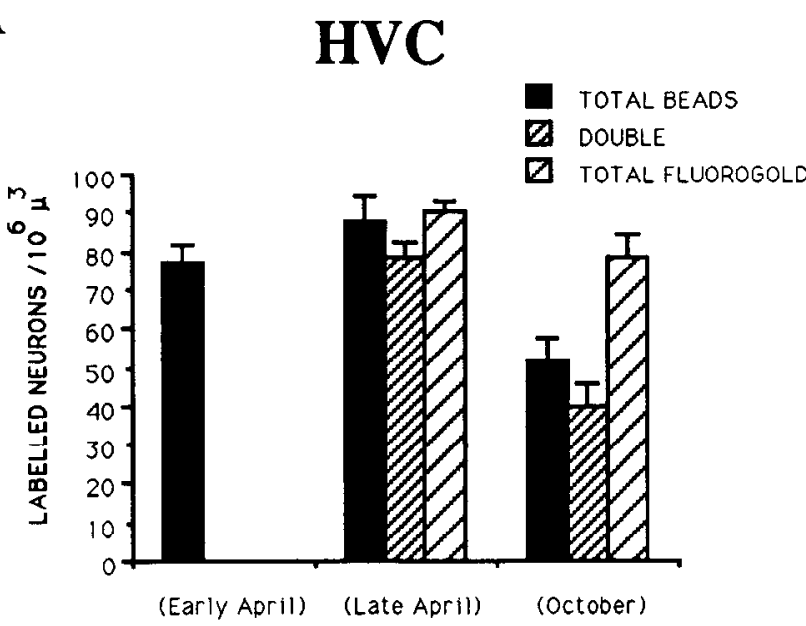

B
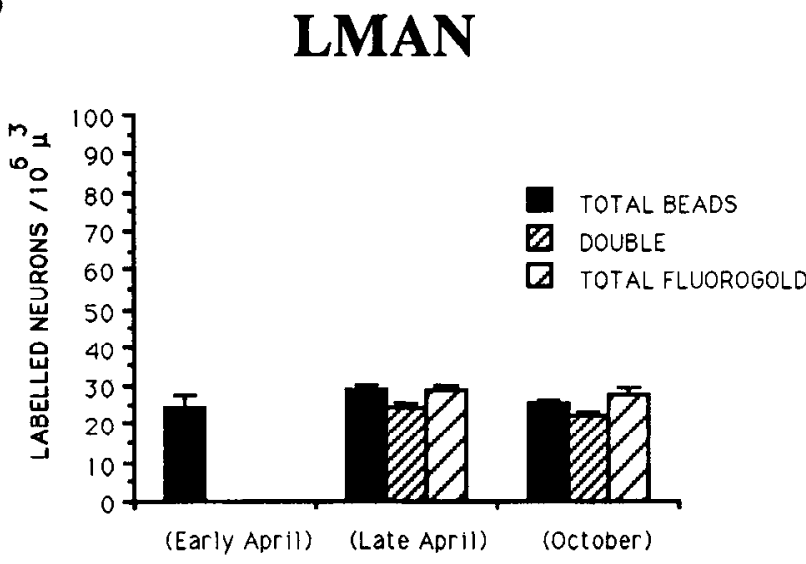

Figure 4. Mean $( \pm$ SEM) retrogradely labeled HVC $(A)$ and LMAN $(B)$ projection neuron densities $4 \mathrm{~d}, 20 \mathrm{~d}$ (in April), and $195 \mathrm{~d}$ (in October) after bead injections into RA. Cell loss/survival over the 6 month study period for the April cohort of RA-projecting neurons in HVC and in LMAN is reflected in bead-labeled cell densities. The overall density of RA-projecting HVC neurons in April and October is represented by the density of fluorogold-labeled cells. Double-labeled cells are those that were backfilled with beads in April and then relabeled with fluorogold $3 \mathrm{~d}$ prior to killing birds in April or October.

$0.023 ;$ double/beads $=0.78, t(4)=36.98, p=0.0001]$. Doublelabeled cell densities were also lower than the densities of cells labeled with fluorogold in late April as well as in October [ for April and October, respectively: double/fluorogold $=0.87, t(3)$ $=6.51, p=0.007 ;$ double/fluorogold $=0.51, t(4)=10.29, p$ $=0.001]$.

There was a significant interaction between survival time and labeling category $[F(2,6)=18.84 ; p=0.003]$. When the analysis was restricted to comparisons of the bead-labeled cohort of HVC neurons at the three different survival times, a highly significant difference in the packing density of these cells was found $[F(2,10)$ $=11.43 ; p=0.003]$. The 4 and $20 \mathrm{~d}$ April survival times were not different $[t(6)=1.35 ; p=0.11]$, but both of these times were associated with significantly higher labeled cell densities than the $195 \mathrm{~d}$ October survival time $[t(7)=3.35, p=0.006$ for 4 vs $195 \mathrm{~d} ; t(7)=4.25, p=0.002$ for 20 vs $195 \mathrm{~d}]$. Between late April and October, there was a $41 \%$ decrease in the density of cells labeled with beads in early April.
The size of the drop in the density of bead-backfilled cells between April and October could be an underestimate of the number of RA-projecting HVC neurons that were lost. That would be the case, for example, if a significant number of the bead-filled cells present in October were non-neuronal. The latter possibility is not overly speculative, since phagocytes or even glia could acquire beads by intake of debris from dying RAprojecting neurons. One way to correct for this possibility is to compare the density of double-labeled cells in April and October. The injection of fluorogold into RA in October and its uptake by bead-labeled cells in HVC allowed us to confirm the neuronal identity of these cells. There was a drop of $49 \%$ in the density of HVC double-labeled cells between April and October $[t(4)=10.29 ; p=0.001]$. Thus, the $41 \%$ drop seen when using beads alone to measure loss may be un underestimate of the proportion of RA-projecting cells that disappeared.

The overall density of RA-projecting HVC neurons in late April and October, as determined by fluorogold injections made $3 \mathrm{~d}$ prior to death, was comparable $[t(7)=1.72 ; p=0.13]$. However, in October birds, there were $35 \%$ more fluorogoldlabeled cells than bead-labeled cells $[t(4)=7.18 ; p=0.002]$, compared to $3 \%$ more in late April $[t(3)=0.69 ; p=0.54]$. These results suggest that $32 \%$ of the RA-projecting HVC neurons present in October were generated and/or developed their RA-projecting phenotype after the April injections of beads. A similar comparison made using double-labeled cells yields $49 \%$ more fluorogold cells than double-labeled in October $[t(4)=$ $10.29 ; p=0.001]$, compared to $13 \%$ in late April $[t(3)=6.51$; $p=0.007$ ], for a net replacement estimate of $36 \%$.

\section{HVC cell sizes}

Size histograms for HVC projection neurons are summarized in Figure 5. The average soma diameters for cells in the April and October RA-projecting neuron populations, identified by fluorogold, were similar [mean $\pm \mathrm{SEM}=7.31 \pm 0.27 \mu \mathrm{m}$ for April, $7.19 \pm 0.15 \mu \mathrm{m}$ for October; $t(7)=0.4 ; p=0.69]$. There was a nonsignificant trend for double-labeled neurons to be larger in April than in October. Mean diameters for this cell category decreased from $7.20 \pm 0.23 \mu \mathrm{m}$ in April to $6.46 \pm$ $0.71 \mu \mathrm{m}$ in October $(t(7)=1.76 ; p=0.11)$. The fraction of cells labeled with fluorogold in October that was not also labeled with beads contained cells that were presumably born or had innervated RA only after bead injections. Neurons in this cohort were significantly larger than the double-labeled cells [8.32 \pm $0.19 \mu \mathrm{m} ; t(4)=6.35 ; p=0.003$ ] and larger than the general population of projection neurons in the same animals as defined by all the cells backfilled with fluorogold, irrespective of whether they were also labeled with beads $[t(4)=8.86 ; p=0.001]$.

\section{LMAN cell densities}

Figure 6 shows photomicrographs of retrogradely labeled LMAN neurons after tracer injections in RA. As was true for HVC, most neurons in LMAN that were labeled initially with beads were also labeled by subsequent injections of fluorogold. A summary of mean ( \pm SEM) densities of LMAN neurons labeled with beads, double-labeled cells, and those labeled with fluorogold at the various survival times is presented in Figure $4 B$. As was true for HVC, the density of double-labeled LMAN neurons was significantly lower than the density of cells labeled with beads or fluorogold irrespective of survival time [main effect, $F(2,6)=36.09, p=0.0001$; double/beads $=0.86$ at $20 \mathrm{~d}, t(3)$ $=5.90, p=0.01 ;$ double/fluorogold $=0.86$ at $20 \mathrm{~d}, t(3)=3.42$, 
$p=0.04 ;$ double/beads $=0.86$ at $195 \mathrm{~d}, t(4)=5.70, p=0.005$; double/fluorogold $=0.81$ at $195 \mathrm{~d}, t(4)=2.40, p=0.07]$.

However, unlike our results for $\mathrm{HVC}$, survival time did not affect the density of cells revealed by different labeling categories in $\operatorname{LMAN}[F(2,6)=15.62, p=0.004$ for nucleus $\times$ label type $\times$ survival time interaction; $F(2,6)=0.19, p=0.83$ for label type $\times$ survival time interaction in LMAN]. Specifically, beadlabeled cell densities in LMAN were not different at the three survival times $[F(2,10)=1.33 ; p=0.31]$. This was also true when comparing fluorogold-labeled cell densities in April and October $[t(7)=0.46 ; p=0.66]$. In addition, bead-labeled neuron densities did not differ from fluorogold-labeled cell densities in late April or in October $(t(3)=0.08, p=0.94$ at $20 \mathrm{~d} ; t(4)=$ $0.70, p=0.52$ at $195 \mathrm{~d}$ ).

\section{LMAN cell sizes}

RA-projecting LMAN neurons were larger than RA-projecting HVC neurons, as defined by cells in both populations that were backfilled by fluorogold, and this was true whether the comparison was done in April or in October [Fig. $7 ; F(1,7)=65.15$; $p=0.0001]$. In addition, the RA-projecting LMAN neurons showed a greater range in backfilled soma profile sizes than was the case for HVC-to-RA projection neurons. The greater range in profile sizes would be expected with a population of cells that has a larger mean diameter. There was a tendency for LMAN cell somas backfilled with fluorogold to be larger in April than in October (mean $\pm \mathrm{SEM}=10.74 \pm 0.45 \mu \mathrm{m}$ for April, 9.61 $\pm 0.44 \mu \mathrm{m}$ for October). However, this difference was not statistically significant $[t(7)=1.75 ; p=0.12$ ). No size differences were found in double-labeled cells between April and October [10.42 $\pm 0.72 \mu \mathrm{m}$ for April, $9.86 \pm 0.56 \mu \mathrm{m}$ for Octobcr; $t$ (7) $=0.63 ; p=0.55]$. There were not enough neurons backfilled exclusively with fluorogold to make a meaningful comparison between the April and October times for this cell category.

\section{Discussion}

The overall packing density of RA-projecting neurons in HVC was found to be the same in April and in October. However, the 6 month interval was also associated with a substantial turnover of cells in this circuit. The magnitude of loss depends on how it was calculated. The lower estimate $(41 \%)$ results from the drop in the density of bead-labeled HVC cells that occurred between 20 and $195 \mathrm{~d}$ after the injection of beads into RA. When loss is measured on the basis of cells containing fluorogold as well as beads, thus ensuring a neuronal phenotype, the higher estimate (49\%) is obtained. This latter criterion is more stringent because it assumes that the relative cfficiency with which ncurons were backfilled with beads in April was comparable to the efficacy with which fluorogold backfilled RA-projecting cells in October. If, for any reason, the ease with which fluorogold was transported from RA to HVC was lower in October, then a subset of RA-projecting, bead-backfilled HVC neurons would fail to appear as double-labeled at this time of year and hence would not be recognized as neuronal. We cannot say, based on our data, which of these estimates is more accurate. The real loss of RA-projecting HVC neurons is likely to fall somewhere between $41 \%$ and $49 \%$.

Previous work using ${ }^{3} \mathrm{H}$-thymidine as a marker for adult neuron production in conjunction with anatomical tracers showed that RA-projecting HVC neurons are produced in adulthood and replace other cells of the same kind (Alvarez-Buylla et al., 1990a; Kirn et al., 1991). The present data suggest that 32-36\%

\section{HVC}

A

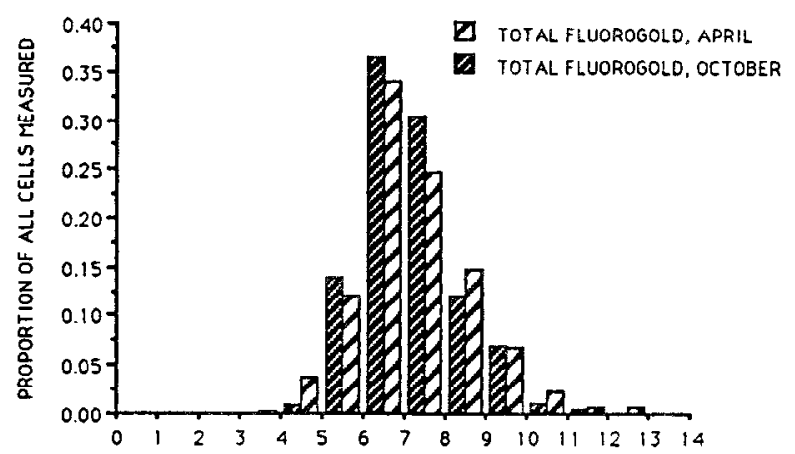

B

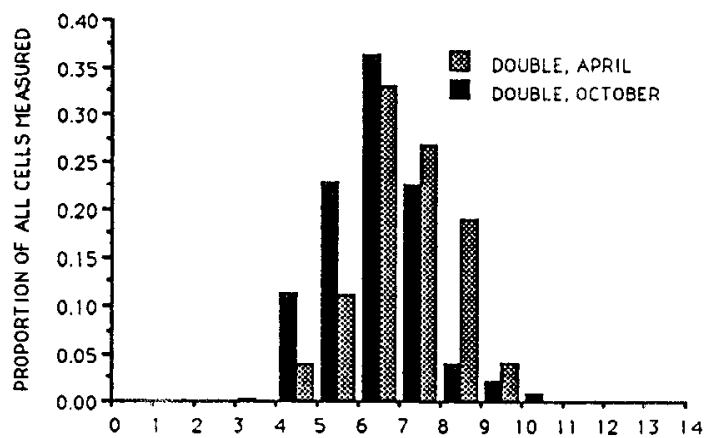

C

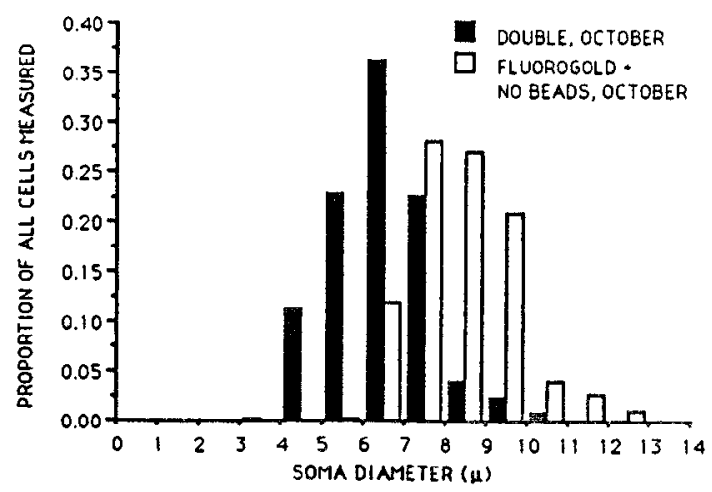

Figure 5. Frequency histograms of soma diameters for retrogradely labeled HVC neurons in late April and in October. Sizes shown are for the general population of RA-projecting HVC neurons labeled with fluorogold $3 \mathrm{~d}$ prior to death (total fuorogold, $A$ ), double-labeled cells that represent the cohort of cells labeled with beads in April and then relabeled with fluorogold in late April or $\operatorname{October}(B)$, and for neurons labeled exclusively with fluorogold in October (fluorogold + no beads, C).

of the RA-projecting neurons present in October had not been in place in April and possibly had been born at a later time. We do not have direct evidence for cell birth, because in the present study ${ }^{3} \mathrm{H}$-thymidine was not used. However, recent work using ${ }^{3} \mathrm{H}$-thymidine indicates that HVC neurons are born during each of the months examined in the present study (Kirn et al., 1992), in support of our more indirect measures using fluorogold.

The 32-36\% gain in RA-projecting neurons was lower than the $41-49 \%$ lost. This could mean that not all of the lost neurons had been replaced by October, or it could mean that fluorogold in October did not backfill all of the RA-projecting HVC neurons that were present, resulting in underestimates of replacement. Given the margin of error associated with each of the measures used, we cannot distinguish between these two alter- 

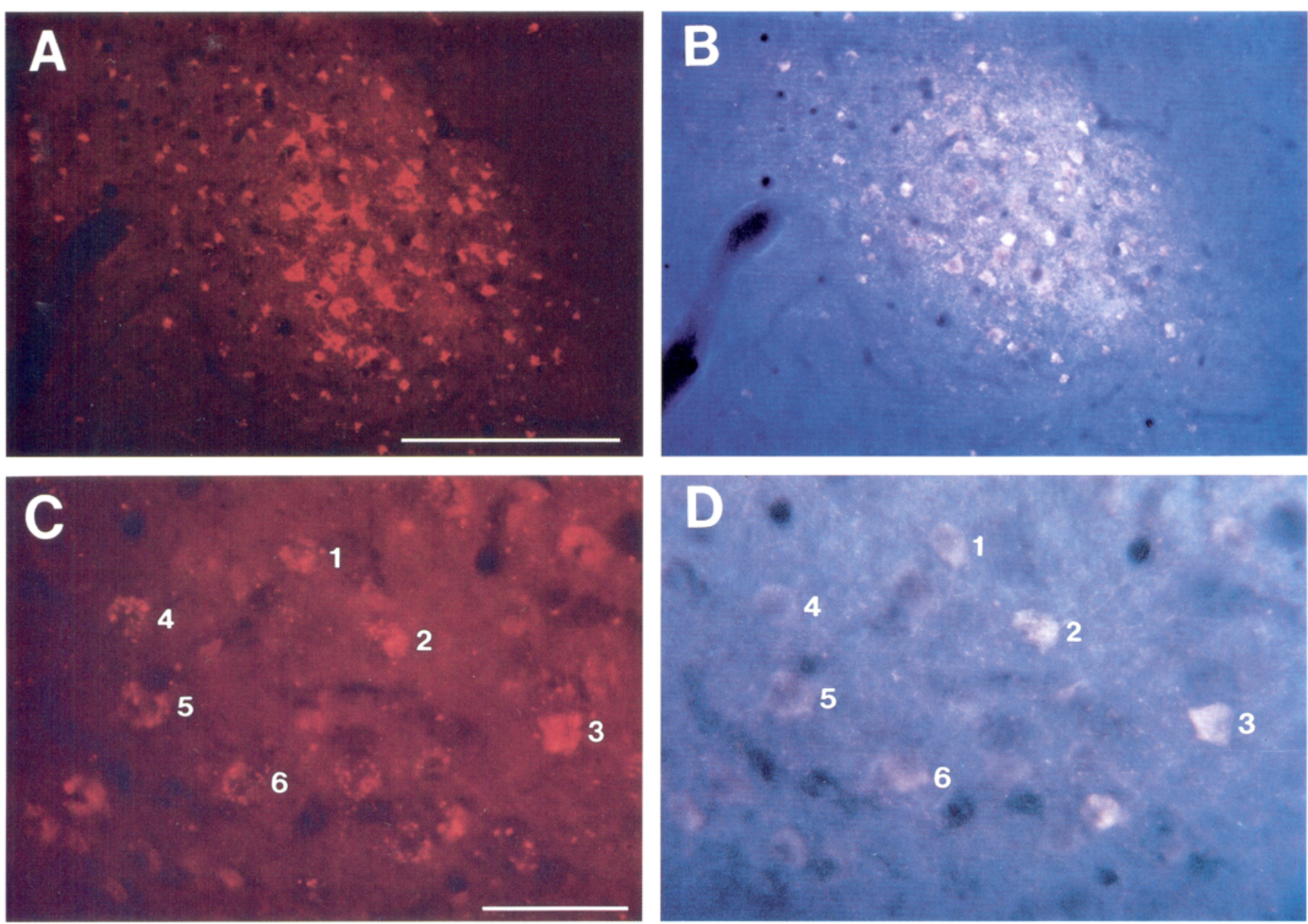

Figure 6. Tracer injections into RA retrogradely label projection neurons in LMAN as well as in HVC. $A$ and $B$ show a low-magnification view of RA-projecting LMAN neurons retrogradely labeled with beads $(A)$, followed $17 \mathrm{~d}$ later by fluorogold $(B)$. $A$ and $B$ are of the same tissue field. Most cells originally labeled with beads became labeled with fluorogold subsequently. $C$ shows a higher-magnification view of bead-labeled LMAN neurons from a bird injected with beads in April and killed $195 \mathrm{~d}$ later. This bird was reinjected in RA with fluorogold $(D) 192 \mathrm{~d}$ after bead injections. $C$ and $D$ are of the same tissue field, and numbers $(1-6)$ correspond to examples of double-labeled cells. Unlike HVC, LMAN did not show a systematic loss of bead-labeled cells over time. Scale bars: $A$ and $B, 200 \mu \mathrm{m} ; C$ and $D, 50 \mu \mathrm{m}$.

natives. Nevertheless, when taken together, the results suggest that between one-third and one-half of the RA-projecting HVC neurons were replaced between April and October.

The $0.3-0.5 \%$ daily rates of ${ }^{3} \mathrm{H}$-thymidine labeling in $\mathrm{HVC}$ reported previously (Alvarez-Buylla et al., 1990a; Kirn et al., 1991) suggested either of two patterns of neuronal replacement: (1) a small number of RA-projecting cells with short life-spans was constantly turning over, or (2) turnover affected a much larger group of cells with longer life-spans. The idea that a small fraction of RA-projecting cells is constantly turning over seemed unlikely based on the finding that RA-projecting HVC neurons born in adult canaries in September persist for at least 8 months (Kirn et al., 1991). Therefore, the percentage of HVC's RAprojecting neurons that are discarded and replaced in any one year could be a sizeable fraction of the total population. A replacement of one-third to one-half over a 6 month period confirms this expectation.

In both HVC and LMAN there were no significant differences between the densities of projection neurons labeled with beads and with fluorogold in the $20 \mathrm{~d}$ survival time. This suggests that the two tracers were equally sensitive markers, as has been shown previously (Kirn et al., 1991). Moreover, most of the cells labeled with one marker were also labeled with the other one, although not all were double labeled. Since the two tracers were injected at different times, the result observed could have been produced by slight differences in the targeting of injections, combined with incomplete fills with either tracer.

Most of the fluorogold-labeled cells backfilled in October that had no fluorescent beads presumably corresponded to RA-projecting HVC cells inserted after the early April bead injections into RA. We cannot conclude that all cells labeled exclusively with fluorogold were new neurons, since some may have simply failed to incorporate beads earlier. This possibility is supported by the fact that double-labeled cell densities were $13 \%$ lower than the densities of fluorogold-labeled cells in the 20 d survival group. When this margin of error is taken into account, we estimate that $87 \%$ of the neurons labeled with fluorogold alone were put in place after bead injections.

The diameter of the putative "young" cells was larger than that of October double-labeled cells that were born at least 6 months earlier, suggesting a possible correlation between the size of these cells and their age. If true, then one might also expect a decrease in the size of double-labeled cells between April and October. RA-projecting HVC neurons in place before 
April showed a tendency to become smaller between April and October, but this trend was not statistically significant. The lack of a significant difference would be expected if many of the soma sizes measured in April corresponded to cells that were already fairly old at that time. Their relatively smaller diameter would lower the mean cell size for April. The cells with the most welldefined ages were those labeled with fluorogold that did not also contain beads, and these cells were the largest RA-projecting cells in HVC.

The apparent reduction in the size of HVC's RA-projecting cells could have come about in either of two ways: (1) the cells became smaller as they grew older, or (2) these cells came in an array of sizes, the larger ones having shorter life-spans. The "aging" hypothesis is supported by recent work that showed that RA-projecting HVC neurons born in adulthood and labeled with ${ }^{3} \mathrm{H}$-thymidine become smaller as they age (Kirn et al., 1991). In this other work the group of neurons studied persisted without any significant losses between September, when they were born, and May. Latex microspheres were not used in this other study, so an age-related reduction in cell size cannot be attributed to the long-term presence of beads in the cell cytoplasm. RA-projecting HVC neurons born in September were also found to be initially larger than the general population of RA-projecting neurons (Kirn et al., 1991), which is consistent with the present findings for cells labeled with fluorogold alone. We do not yet know the possible functional correlates of cell shrinkage. However, since reduction in the size of HVC's RAprojecting cells occurs as cells grow older, it is intriguing to wonder whether shrinkage might be part of a process that eventually leads to the death and replacement of these HVC cells.

Our use of retrogradely transported beads to study neuron survival is not without potential sources of error. There are risks associated with using any invasive technique to study the natural processes of cell loss. However, LMAN cells that projected to RA and that were backfilled with beads were present in comparable densities 20 and $195 \mathrm{~d}$ later, suggesting that this procedure, by itself, need not lead to cell death. Beads have also been used as a long-term marker for HVC neurons that project to area X (Gahr, 1990). These cells, like those in LMAN, are not replaced in adulthood (Alvarez-Buylla et al., 1988), and the number of bead-labeled cells projecting from HVC to area X did not decline after survival times of 7 months. The possibility remains that the treatment of beads by neither LMAN cells that project to RA nor $\mathrm{HVC}$ cells that project to area X mimics the treatment of beads by RA-projecting HVC neurons. For example, such beads could have been subjected to exocytosis in the latter group of cells. We do not have a control for this possibility. However, the fact remains that the level at which new RA-projecting neurons are added to HVC (Alvarez-Buylla et al., 1990a; Kirn et al., 1991) is comparable in magnitude to the losses observed among the bead-backfilled HVC neurons that project to RA. Taken together, the evidence of cell birth and the evidence of cell death are remarkably consistent for a number of different neuronal populations.

A second possible source of error in measuring cell loss with beads concerns the fact that we do not know how long this tracer remains available for retrograde transport at the injection site. Unlike ${ }^{3} \mathrm{H}$-thymidine, which is only available for uptake by dividing cells for $60-90 \mathrm{~min}$ in the canary (Alvarez-Buylla et al., 1990b), beads may be transported for several days. Deposits of beads persisted at the injection site even in our longest survival group. The potential exists for labeling not only cells pres-
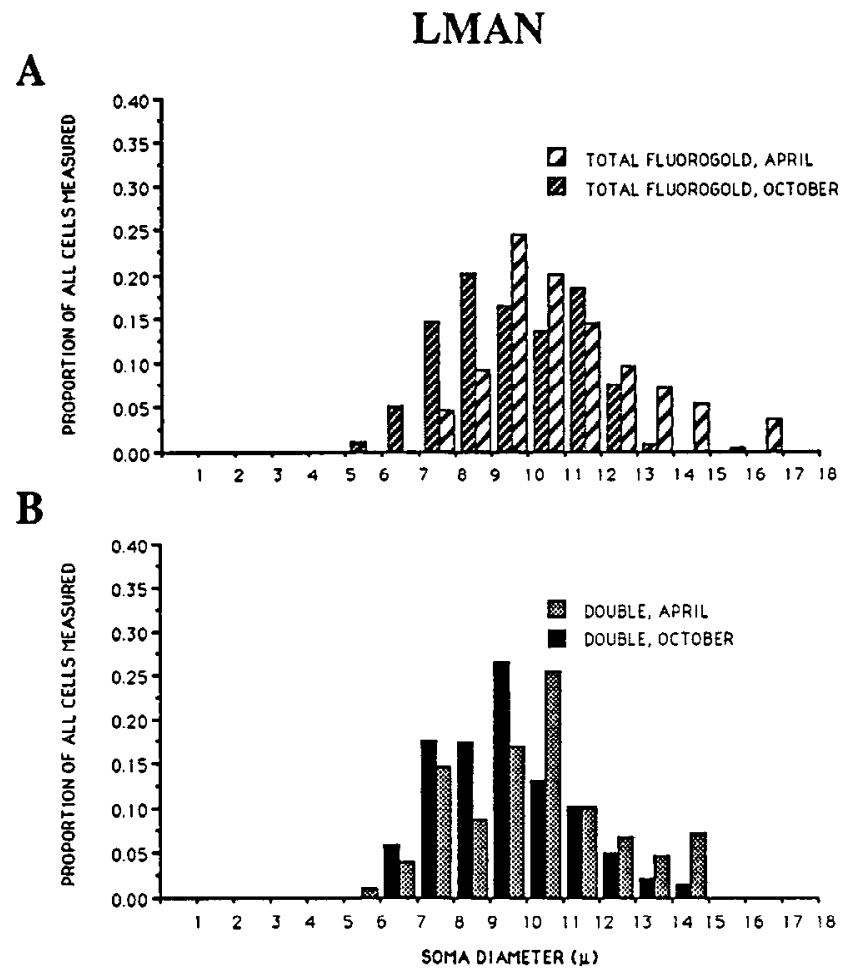

Figure 7. Frequency histograms of soma diameters for retrogradely labeled LMAN neurons in late April and in October. Sizes shown are for the general population of RA-projecting LMAN neurons labeled with fluorogold $3 \mathrm{~d}$ prior to death (total fluorogold, $A$ ) and doublelabeled cells that represent the cohort of cells labeled with beads in April and then relabeled with fluorogold in April or October $(B)$. There were not enough cells labeled exclusively with fluorogold (fluorogold + no beads) to make meaningful comparisons of sizes between April and October.

ent at the time of tracer injections, but also those cells born within an unknown amount of time after the injections. If, in the present work, beads remained available for transport for more than $20 \mathrm{~d}$, this would result in underestimates of loss between our 20 and $195 \mathrm{~d}$ survival times. We found no significant differences in the density of bead-labeled cells between 4 and $20 \mathrm{~d}$ survivals in April, and this can be taken as evidence that bead transport ceased prior to the $20 \mathrm{~d}$ death time.

HVC neuron production occurs in adult canary at all times of year (Paton et al., 1985; Alvarez-Buylla et al., 1990a; Kirn et al., 1991; F. Nottebohm, unpublished observations). Counts of pyknotic, degenerating $\mathrm{HVC}$ cells indicate that cell death also occurs on a continuous basis (Kirn et al., 1992). We do not yet know whether HVC projection neuron loss occurs at similar rates throughout the year or is especially high at certain times; we do not have data comparable to those presented here for other times of the year. However, HVC neuron number remains relatively stable (Kirn et al., 1991), and so if there are waves of cell loss, they must be mirrored by waves of cell addition, and vice versa. Remarkably, based on the present results, the process of neuron replacement may be repeated several times during the course of a canary's life, as recruitment of new HVC projection neurons is similar in 1- and 4-year-old canaries (AlvarezBuylla et al., 1990a), and these birds can live 10 or more years.

We do not yet know the role played by RA-projecting HVC neurons that turnover in adulthood, but they may serve important functions in the production and perception of learned song (for review, see Nottebohm, 1989; Nottebohm et al., 1990). 
In males, lesions in $\mathrm{HVC}$ or RA produce severe deficits in song production (Nottebohm et al., 1976) and the HVC-to-RA pathway also conveys short-latency responses to sound (Williams and Nottebohm, 1985; Williams, 1989). HVC lesions in adult female canaries decrease selectivity to conspecific song, as measured by the solicitation display (Brenowitz, 1991). RA neurons respond preferentially to playbacks of the bird's own song, and this selectivity disappears if HVC's input to RA is interrupted (Doupe and Konishi, 1991; D. S Vicario and K. H. Yohay, unpublished observations).

The $41-49 \%$ loss of HVC's RA-projecting neurons observed in the present experiment occurred between spring and fall, which corresponds to the time when adult male canaries go from a breeding to a nonbreeding condition and from stereotyped song to plastic song. It is during that time, too, that these birds produce the greatest yearly changes in their song repertoire (Nottebohm et al., 1986). The HVC-to-RA part of the circuit for song control must undergo substantial synaptic remodeling to accommodate the magnitude of loss and replacement observed in the present experiment. This remodeling may be associated with changes in motor programs for song and/or programs that guide perceptual learning. Still could not all these changes take place while preserving the existing set of neurons? Or, to put it more bluntly, why replace neurons at all? Learning is thought to change brain circuits in a long-lasting manner. It may be that in the avian brain long-term memories produce irreversible changes in some neurons, limiting their ability to encode new memories. The acquisition of new information may require that old information - and the cells that hold it-be discarded. This scenario, speculative and suggested before (Nottebohm, 1985), seems now to focus attention on the projection neurons that link HVC to RA. Projection neurons of this kind are also produced in juvenile songbirds at the time they are acquiring their learned song (Alvarez-Buylla et al., 1988, 1992; Nordeen and Nordeen, 1988). Are these neurons and the connections they form the repositories of long-term song memories?

It would be interesting to know if the entire circuit between HVC and RA is lost and replaced annually or if there is a subpopulation of these cells that persist for longer time intervals. Although the canary modifies its song substantially from year to year, some syllables are retained from one breeding season to the next (Nottebohm et al., 1987). Complete turnover of RAprojecting HVC neurons in 12 months would suggest that memories for persistent song syllables are stored by the brain in the absence of a stable subpopulation of these cells. Now that we know that much of the projection pathway between HVC and RA is normally replaced, the stage is set to assess the impact of experimental regulation of neuron turnover on song plasticity. The canary may teach us valuable lessons about mechanisms of learning and brain rejuvenation.

\section{References}

Alvarez-Buylla A (1992) Neurogenesis and plasticity in the CNS of adult birds. Exp Neurol 115:110-114.

Alvarez-Buylla A, Nottebohm F (1988) Migration of young neurons in adult avian brain. Nature 335:353-354.

Alvarez-Buylla A, Vicario DS (1988) Simple microcomputer system for mapping tissue sections with the light microscope. J Neurosci Methods 25:165-173.
Alvarez-Buylla A, Theelen M, Nottebohm F (1988) Birth of projection neurons in the higher vocal center of the canary forebrain before, during, and after song learning. Proc Natl Acad Sci USA 85:87228726

Alvarez-Buylla A, Kirn JR, Nottcbohm F (1990a) Birth of projection neurons in adult avian brain may be related to perceptual or motor learning. Science 249:1444-1446.

Alvarez-Buylla A, Theelen M, Nottebohm F (1990b) Proliferation "hot spots" in adult avian ventricular zone reveal radial cell division. Neuron 5:101-109.

Alvarez-Buylla A, Ling C-Y, Nottebohm F (1992) High vocal center growth and its relation to neurogenesis, neuronal replacement and song acquisition in juvenile canaries. J Neurobiol 23:396-406.

Bottjer SW, Halsema KA, Brown SA, Miesner EA (1989) Axonal connections of a forebrain nucleus involved with vocal learning in zebra finches. J Comp Neurol 279:312-326.

Brenowitz EA (1991) Altered perception of species-specific song by female birds after lesion of a forebrain nucleus. Science 251:303-305.

Canady RA, Burd GD, DeVoogd TJ, Nottcbohm F (1988) Effect of testosterone on input received by an identified neuron type of the canary song system: a Golgi/electron microscopy/degeneration study. J Neurosci 8:3770-3784.

Divac I, Mogensen J (1990) Long-term retrograde labelling of neurons. Brain Res 524:339-341.

Doupe AJ, Konishi M (1991) Song-selective auditory circuits in the vocal control system of the zebra finch. Proc Natl Acad Sci USA 88: $11339-11343$.

Gahr M (1990) Delineation of a brain nucleus: comparisons of cytochemical, hodological, and cytoarchitectural views of the song control nucleus HVC of the adult canary. J Comp Neurol 294:30-36.

Katz LC, Burkhalter A, Dreyer WJ (1984) Fluorescent latex microspheres as a retrograde neuronal marker for in vivo and in vitro studies of visual cortex. Nature 310:498-500.

Kirn JR, Alvarez-Buylla A, Nottebohm F (1991) Production and survival of projection neurons in a forebrain vocal center of adult male canaries. J Neurosci 11:1756-1762.

Kirn JR, Kasparian S, Nottebohm F (1992) A temporal relationship between neurogenesis and neuronal death in the high vocal center of the adult canary. Soc Neurosci Abstr 18:770.

Madison R, Macklis JD, Thies C (1990) Latex nanosphere delivery system (LNDS): novel nanometer-sized carriers of fluorescent dyes and active agents selectively target neuronal subpopulations via uptake and retrograde transport. Brain Res 522:90-98.

Morrison RG (1991) Neural correlates of sensitive periods for song learning in zebra finches. $\mathrm{PhD}$ thesis, The Rockefeller University.

Nordeen KW, Nordeen EJ (1988) Projection neurons within a vocal motor pathway are born during song learning in zebra finches. Nature 334:149-151.

Nottebohm F (1985) Neuronal replacement in adulthood. Ann NY Acad Sci 457:143-161.

Nottebohm F (1989) From bird song to neurogenesis. Sci Am 260: $74-79$.

Nottebohm F, Stokes TM, Leonard CM (1976) Central control of song in the canary Serinus canarius. J Comp Neurol 165:457-486.

Nottebohm F, Kelley DB, Paton JA (1982) Connections of vocal control nuclei in the canary telencephalon. J Comp Neurol 207:344357.

Nottebohm F, Nottebohm ME, Crane L (1986) Developmental and seasonal changes in canary song and their relation to changes in the anatomy of song-control nuclei. Behav Neural Biol 46:445-471.

Nottebohm F, Nottcbohm ME, Cranc LA, Wingficld JC (1987) Scasonal changes in gonadal hormone levels of adult male canaries and their relation to song. Behav Neural Biol 47:197-211.

Nottebohm F, Alvarez-Buylla A, Cynx J, Kirn JR, Ling C-Y, Nottebohm M, Suter R, Tolles A, Williams H (1990) Song learning in birds: the relation between perception and production. Philos Trans R Soc Lond [Biol] 329:115-124.

Paton JA, O'Loughlin BO, Nottebohm F (1985) Cells born in adult canary forebrain are local interneurons. J Neurosci 5:3088-3093.

Schmued LC, Fallon JH (1986) Fluoro-gold: a new retrograde axonal tracer with numerous unique properties. Brain Res 377:147-154.

Stokes TC, Leonard CM, Nottebohm F (1974) A stereotaxic atlas of 
the telencephalon, diencephalon, and mesencephalon of the canary Serinus canarius. J Comp Neurol 156:337-374.

Vicario DS, Simpson HB (1988) Control of syringeal muscles in nucleus RA of zebra finches. Soc Neurosci Abstr 14:89.

Weibel ER (1979) Stereological methods. Vol 1, Practical methods for biological morphometry. New York: Academic.
Williams H (1989) Multiple representations and auditory-motor interactions in the avian song system. Ann NY Acad Sci 563:148-164. Williams H, Nottebohm F (1985) Auditory responses in avian vocal motor neurons: a motor theory for song perception in birds. Science 229:279-282. 